\title{
Spectrochemical Analysis of Bottled and Tap Water from Selected Counties of Middle Tennessee, USA
}

\author{
Aminul Islam Chowdhury1, Ravneet Kaur², Anonya Akuley-Amenyenu², \\ Abua Ikem³, Sam 0. Dennis ${ }^{2 *}$ \\ ${ }^{1}$ Department of Applied Chemistry and Chemical Engineering, University of Chittagong, Chittagong, Bangladesh \\ ${ }^{2}$ Department of Agricultural and Environmental Sciences, Tennessee State University, Nashville, TN, USA \\ ${ }^{3}$ Department of Agriculture and Environmental Sciences, Lincoln University, Jefferson City, MO, USA \\ Email: ^sdennis@tnstate.edu
}

How to cite this paper: Chowdhury, A.I., Kaur, R., Akuley-Amenyenu, A., Ikem, A. and Dennis, S.O. (2021) Spectrochemical Analysis of Bottled and Tap Water from Selected Counties of Middle Tennessee, USA. Journal of Water Resource and Protection, 13, 20-31.

https://doi.org/10.4236/jwarp.2021.131002

Received: June 1, 2020

Accepted: January 18, 2021

Published: January 21, 2021

Copyright (c) 2021 by author(s) and Scientific Research Publishing Inc. This work is licensed under the Creative Commons Attribution International License (CC BY 4.0).

http://creativecommons.org/licenses/by/4.0/

\begin{abstract}
A total of 37 elements were determined in tap and bottled water samples from six counties of Middle Tennessee (USA) by Inductively Coupled Plasma Optical Emission Spectrometry (ICP-OES). The overarching goal of the study is to dispel the myth that bottled water is better than tap water or vice versa. Other parameters analyzed were $\mathrm{pH}$, conductivity, and Total Dissolved Solids (TDS). The results were compared with the Maximum Contaminant Limit (MCL) reported by the US Environmental Protection Agency (US-EPA). The concentrations of phosphorus, silicon, fluoride, and chloride conformed to the established values by US-EPA maximum contaminant level corresponding value. The level of Aluminum (Al), Boron (B), Chromium (Cr), Cobalt (Co), Copper (Cu), Iron (Fe), Lithium (Li), Manganese $(\mathrm{Mn})$, Nickel $(\mathrm{Ni})$, Titanium $(\mathrm{Ti})$, Vanadium $(\mathrm{V})$, and Zinc $(\mathrm{Zn})$ conformed to the established values by governmental agencies (USEPA). Heavy metals such as Arsenic (As), Cadmium (Cd), Cobalt (Co), Lead ( $\mathrm{Pb}$ ), Mercury $(\mathrm{Hg})$, and Silver $(\mathrm{Ag})$ were detected in the tap water of the urban (Davidson) and urbanizing (Rutherford and Williamson) counties; suggesting that rural counties had a less heavy metal concentration in their drinking water sources than urban counties $(\mathrm{P}<0.05)$. However, the values were below the Maximum Contaminant Levels (MCLs).
\end{abstract}

\section{Keywords}

Heavy Metals, Fluoride, ICP-OES, Maximum Contaminant Level (MCL), Principal Component Analysis (PCA), Cluster Analysis 


\section{Introduction}

In recent times, concern over drinking water quality and availability has become important to the global community, especially with population growth, coupled with rapid urbanization, changing lifestyles and economic development. The presence of toxic chemicals, radionuclides, and nitrates/nitrites in drinking water may cause adverse effects on human health. Ailments such as cancer, bodily malfunctions, and chronic illnesses are among the human health conditions that may be associated with impaired drinking water sources [1]. Hexavalent chromium Cr (VI) [2] and Arsenic [3] [4] are potential contaminants in drinking water resources. This has remained a compelling challenge in many parts of the United States, as well as in regions affected by industrial pollution.

Arsenic has been found to easily migrate from contaminated soil into groundwater under different geochemical conditions [5] [6]. Public water systems are regulated with a current drinking water standard for arsenic at $10 \mathrm{ppb}$ under the Safe Drinking Water Act [7]. An ecological study conducted across Iowa State in the US [3] has shown a significant dose-dependent positive association between low-level arsenic exposure from drinking water and prostate cancer. On the other hand, combination of poor wastewater management practices and natural geological formations have led to Chromium's wide occurrence in many communities' drinking water resources. On average filtration was found to remove a considerable amount of calcium $(\mathrm{Ca})$ from the water, removing as much as about $89 \%$ of $\mathrm{Ca}[8]$.

A major challenge, therefore, is providing maximum protection and monitoring strategies for drinking water sources. Consequently, in the last few decades, the consumption of bottled water has increased rapidly [9] and more than half of the American population drink bottled water. Additionally, about a third of the public in the United States consume bottled water regularly [10] [11].

Freshwater education is important from an early age. A combination of different factors, including changes in the social role of science, complexity and uncertainty contributed to the emergence of the public perception which plays an important role in the choice of bottled water over tap water. Despite the work developed in this area, there are knowledge gaps and there is the need for research to fill these gaps [12].

The objectives of the study were 1) to describe the inorganic trace elements content of tap, and bottled waters from Middle Tennessee counties (United States); 2) to compare the drinking water quality measured values with regulatory threshold values to ensure the safety of the public; and 3) to apply cluster analysis and principal component analysis to understand the similarities/dissimilarities and the underlying controlling factors in the drinking water dataset.

Inductively coupled plasma optical emission spectrometry (ICP-OES) is a powerful technique to deter-mine $\mathrm{Pb}, \mathrm{Hg}$ and various other trace elements in various matrices [13] [14]. Inductively Coupled Plasma Optical Emission Spec- 
troscopy (ICP-OES) has become the tool of choice for routine analysis of liquid samples as well as materials that can be easily turned into a liquid form by dissolution or digestion. Its employs spectroscopes and spectrographs for visual evaluation of spectral lines on a film [15].

\section{Materials and Methods}

\subsection{Study Location}

Six counties from Middle Tennessee namely Canon, Coffee, Davidson, Rutherford, Warren, and Williamson were chosen for the collection of the tap water samples (Figure 1 and Figure 2). These counties were chosen because they represent Urban, Urbanizing and Rural settings in Middle Tennessee. According to the US Census Bureau [16], one county is considered urban, two as urbanizing, and three as rural. The Davidson county (population 648,295) is an urban county, while Rutherford (population 274,454) and Williamson (population $192,911)$ counties are urbanizing. On the other hand, the rural counties are Canon (population 3811), Coffee (population 53,222), and Warren (population

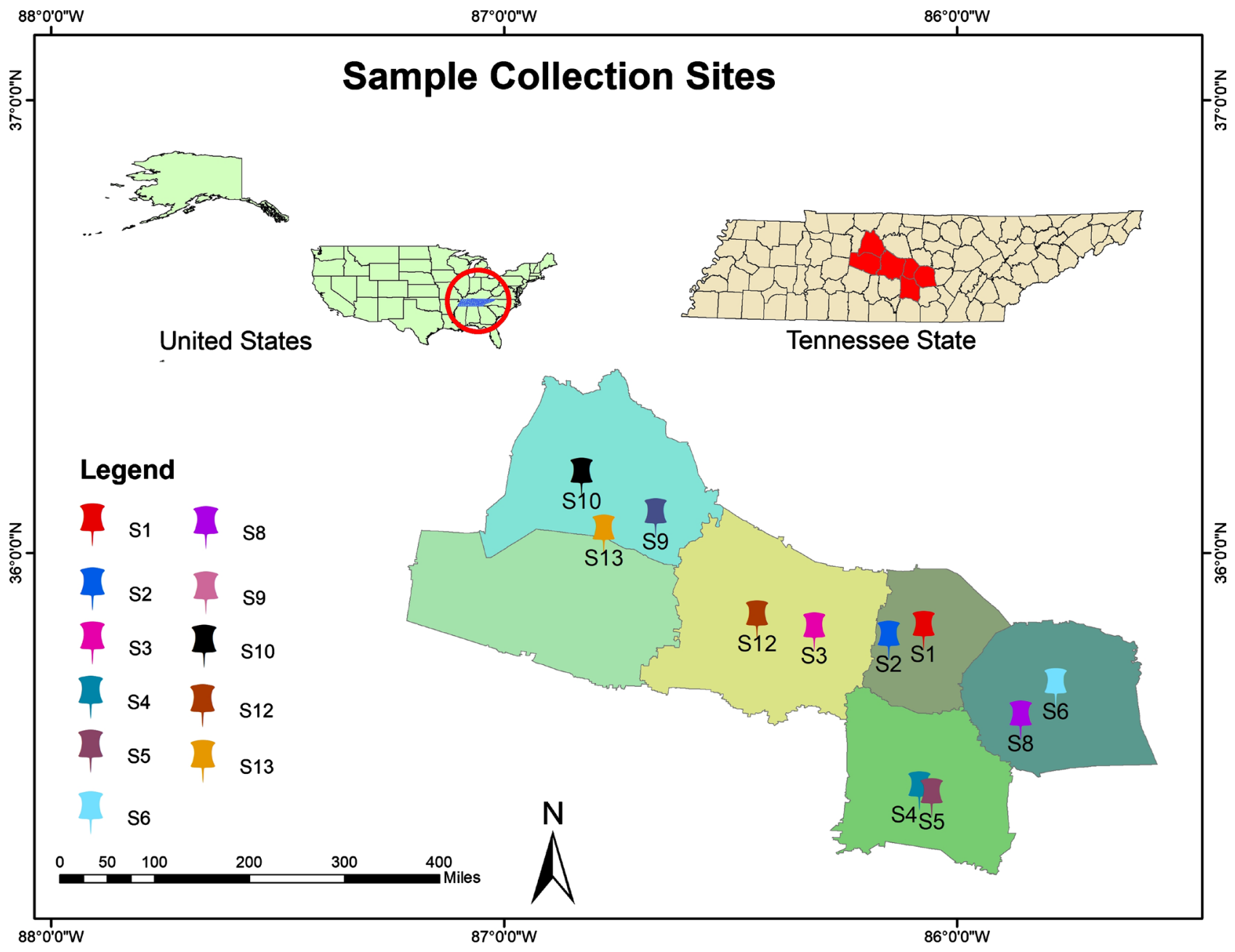

Figure 1. GIS map showing the sample collection points. 


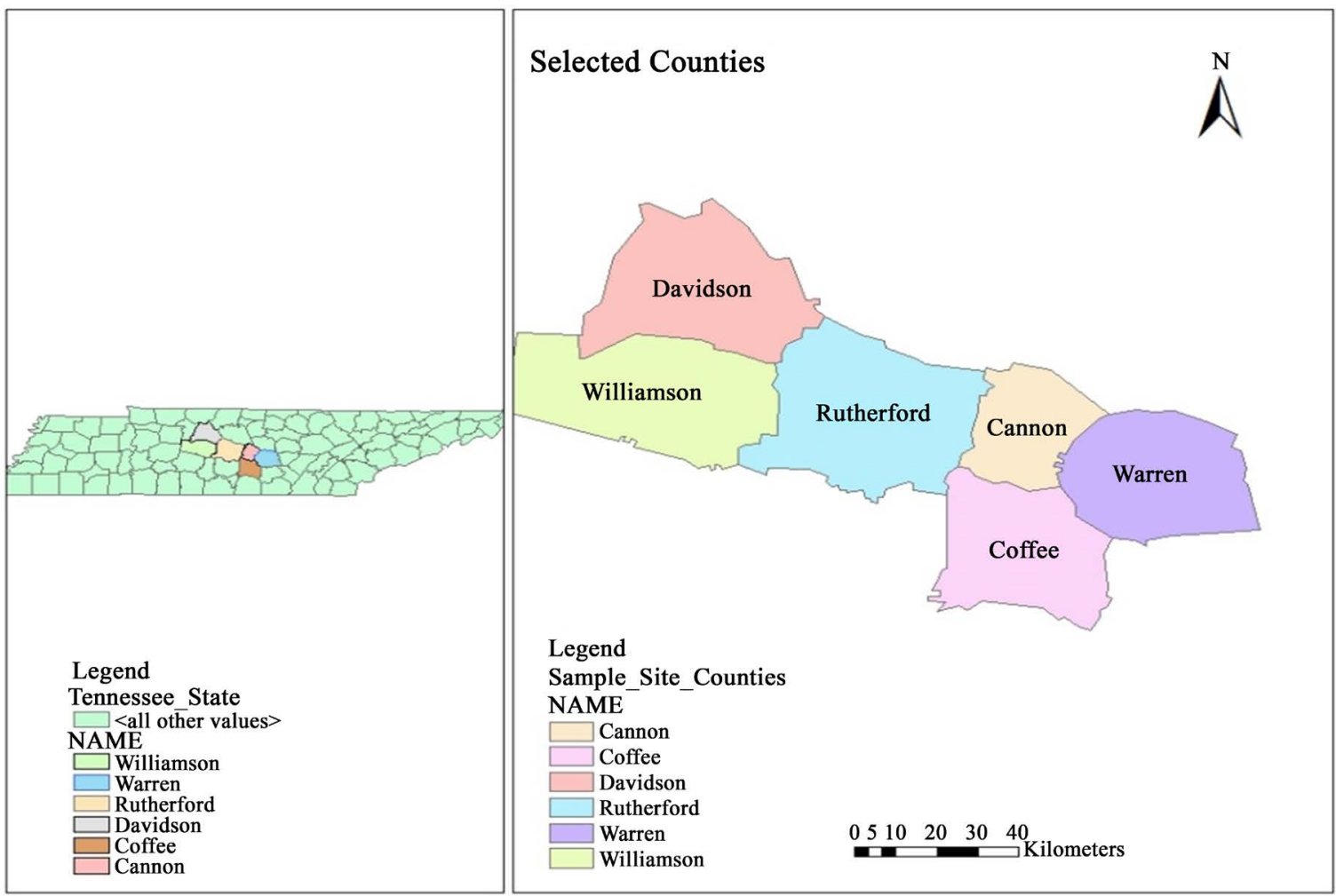

Figure 2. GIS Map showing the 6 counties in the middle Tennessee for the drinking water sampling.

39,839). The tap water samples were collected from three locations in each county. Tap water was collected randomly from six counties in Middle Tennessee while 12 different brands of bottled water were purchased from various supermarkets. Most of the selected sampling locations were publicly accessible places such as supermarkets, gas stations, and food courts or restaurants.

\subsection{Reagents and Materials}

Tap water samples were collected randomly from three different locations within each county. The tap water samples were collected between May 2012 and July 2013. Bottled water was also purchased during the same period. A total of 18 tap water samples were collected from the selected six counties (Table 1). Pre-cleaned sterilized plastic bottles were used to collect the water samples. The water samples were transported to the laboratory. Elemental constituents were determined using ICP-OES.

All the chemicals used in the analysis of the water samples were reagent grade and were purchased from Fisher Scientific (Suwanee GA, USA) and Hach (Loveland, CO, USA). Distilled water was used as feed water to produce ultra-pure deionized water by the Nano-pure Infinity UV/UF Deionizer (Barnstead Thermolyne, IA, USA; resistivity: $18.3 \mathrm{~m} \Omega / \mathrm{cm}$ at room temperature and TOC: < $\mu \mathrm{g} / \mathrm{L})$. A mixed standard (100 $\mathrm{mg} / \mathrm{L}$ containing a suite of elements) was purchased from SPEX Certiprep, Inc. (Metuchen, NJ, USA). Other metal standards (1000-mg/L each) for the calibration of the ICP were also purchased from Fisher 
Scientific. The method for the analysis of elements in samples was validated with Standard Reference Material (SRM 1643e Trace elements in natural water). A Varian Vista-Pro ICP-OES (Varian Inc., Walnut Creek, CA 94598, USA) was used for the measurement.

The ICP-OES was calibrated using calibration standard solutions made from the stock standard solutions. Additionally, an internal standard (scandium) was used as part of quality assurance. SRM 1643e was used to check the accuracy and precision of the analytical method. The Standard Reference Material (SRM 1643e): trace elements in natural water, was purchased from the National Institute of Standards and Technology (NIST), Gaithersburg, MD, USA.

\subsection{Drinking Water Collection}

Tap water samples were collected randomly from three different locations within each county. A total of 18 tap water samples were collected from the selected six counties (Table 1). While microbial work was not done in this study, pre-cleaned sterilized plastic bottles were used to collect the water samples. The water samples were shipped to the laboratory for analysis. Elemental constituents were determined using ICP-OES. The collected water samples did not contain any particulates; hence the water samples were not filtered prior to analysis. The Operation condition of the Inductively Coupled Plasma is illustrated in Table 2.

Table 1 . The tap water collection sites.

\begin{tabular}{|c|c|c|c|c|}
\hline County & Settings & Zip code & Longitude & Latitude \\
\hline Canon & Rural & 37,190 & -82.478883 & 36.292454 \\
\hline Canon & Rural & 37,190 & -86.150084 & 35.806863 \\
\hline Canon & Rural & 37,190 & -86.314514 & 35.824953 \\
\hline Coffee & Rural & 37,355 & -86.082443 & 35.474297 \\
\hline Coffee & Rural & 37,355 & -86.04591 & 35.455325 \\
\hline Coffee & Rural & 37,355 & -86.055132 & 35.458683 \\
\hline Warren & Rural & 37,110 & -85.780997 & 35.702216 \\
\hline Warren & Rural & 37,357 & -85.883143 & 35.619804 \\
\hline Warren & Rural & 37,357 & -85.858805 & 35.630702 \\
\hline Davidson & Urban & 37,013 & -86.664539 & 36.077627 \\
\hline Davidson & Urban & 37,209 & -86.826616 & 36.165698 \\
\hline Davidson & Urban & 37,209 & -86.828549 & 36.166975 \\
\hline Rutherford & Urbanizing & 37,129 & -86.448390 & 35.869310 \\
\hline Rutherford & Urbanizing & 37,129 & -86.445811 & 35.856169 \\
\hline Rutherford & Urbanizing & 37,129 & -86.430227 & 35.847209 \\
\hline Williamson & Urbanizing & 37,027 & -86.792645 & 36.026294 \\
\hline Williamson & Urbanizing & 37,027 & -86.778694 & 36.041272 \\
\hline Williamson & Urbanizing & 37,027 & -86.779471 & 36.040965 \\
\hline
\end{tabular}


Table 2. Instrument operational parameters and conditions for the ICP-OES.

\begin{tabular}{cc}
\hline Plasma flow & $15 \mathrm{~L} / \mathrm{min}$ \\
Auxiliary flow & $1.5 \mathrm{~L} / \mathrm{min}$ \\
Nebulizer flow & $0.75 \mathrm{~L} / \mathrm{min}$ \\
Replicate read time & $3 \mathrm{~s}$ \\
Instr. Stabilization delay & $15 \mathrm{~s}$ \\
Sample uptake delay & $40 \mathrm{~s}$ \\
Pump rate & $15 \mathrm{rpm}$ \\
Rinse time & $20 \mathrm{~s}$ \\
Fast pump (sample delay/rinse) & $\mathrm{ON}$ \\
Replicates & 3 \\
\hline
\end{tabular}

Milli-Q water (resistivity of $18.2 \mathrm{M} \Omega / \mathrm{cm}$ ) was used for sample dilutions, rinses and preparation of diluted standards. All glassware and polyethylene containers in contact with sample digests were washed with metal-free soap, rinsed multiple times, soaked in 50\% nitric acid for 24 hours and finally rinsed with deionized water. The trace metal grade concentrated nitric acid was used as a reagent and purchased from Fisher Scientific (St. Louis, Missouri, USA). The ICP tune and calibration solutions were from SPEX Certiprep, Inc. (Metuchen, NJ, USA). Standard reference material (SRM 1640: trace elements in natural water) (Table 3) was purchased from the National Institute of Standards and Testing (NIST), Gaithersburg, MD 20899, USA. The SRM samples were used in recovery and method validation experiments (Table 3 ).

The percentage trace element recoveries (Table 3 ) from the standard reference materials were close to the provided certified values by the manufacturers. Recoveries ranged from 70\% - 120\%. The measured values of SRM 1643 used as an ICP check solution were also close to the certified values reported by NIST (data not reported).

The elements determined by ICP-OES were Aluminum (Al), Antimony (Sb), Arsenic (As), Boron (B), Barium (Ba), Beryllium (Be), Bismuth (Bi), Calcium (Ca), Cadmium (Cd), Cobalt (Co), Chromium (Cr), Copper ( $\mathrm{Cu}$ ), Gallium ( $\mathrm{Ga})$, Indium (In), Iron ( $\mathrm{Fe})$, Lead $(\mathrm{Pb})$, Lithium $(\mathrm{Li})$, Magnesium $(\mathrm{Mg})$, Manganese (Mn), Mercury (Hg), Molybdenum (Mo), Nickel (Ni), Phosphorus (P), Potassium (K), Rubidium (Rb), Selenium (Se), Sodium (Na), Silicon (Si), Silver (Ag), Strontium (Sr), Sulfur (S), Thallium (Tl), Tin (Sn), Titanium (Ti), Uranium (U), Vanadium (V), and Zinc (Zn).

The physicochemical parameters such as $\mathrm{pH}$, specific conductivity, Total Dissolved Solids (TDS) were determined in tap water and compared with the US Environmental Protection Agency Maximum Contaminant Level (MCL). These parameters were found to be below their respective MCL limit (Table 4).

\section{Statistical Analysis}

Statistical analysis was performed using SAS (Version 9.3; SAS Institute Cary, 
Table 3. Elemental concentrations (mg/kg dry wt.) in Standard Reference Materials (SRM) value vs. measured value of trace elements.

\begin{tabular}{|c|c|c|c|}
\hline Elements & $\begin{array}{l}\text { SRM 1643e Certified } \\
\text { Value }(\mu \mathrm{g} / \mathrm{L})^{\mathrm{a}}\end{array}$ & $\begin{array}{c}\text { Mean Measured Value } \\
(\mu \mathrm{g} / \mathrm{L})\end{array}$ & Recovery (\%) \\
\hline Aluminum & $141.8 \pm 8.6$ & 133.713 & 94.29 \\
\hline Antimony & $58.30 \pm 0.61$ & 46.376 & 79.55 \\
\hline Arsenic & $60.45 \pm 0.72$ & 54.301 & 89.83 \\
\hline Barium & $544.2 \pm 5.8$ & 480.706 & 88.33 \\
\hline Beryllium & $13.98 \pm 0.17$ & 13.335 & 95.39 \\
\hline Bismuth & $14.09 \pm 0.15$ & 14.079 & 99.92 \\
\hline Boron & $157.9 \pm 3.9$ & na & na \\
\hline Cadmium & $6.568 \pm 0.073$ & 5.311 & 80.86 \\
\hline Calcium & $32.300 \pm 1.100$ & 28226.9 & 87.39 \\
\hline Chromium & $20.40 \pm 0.24$ & 18.534 & 90.85 \\
\hline Cobalt & $27.06 \pm 0.32$ & 21.647 & 79.99 \\
\hline Copper & $22.76 \pm 0.31$ & 23.367 & 102.6 \\
\hline Iron & $98.1 \pm 1.4$ & 87.97 & 89.67 \\
\hline Lead & $19.63 \pm 0.21$ & 13.789 & 70.24 \\
\hline Lithium & $17.4 \pm 1.7$ & 20.282 & 116.56 \\
\hline Magnesium & $8.037 \pm 98$ & 7053.1 & 87.76 \\
\hline Manganese & $38.97 \pm 0.45$ & 34.991 & 89.79 \\
\hline Molybdenum & $121.4 \pm 1.3$ & 116.976 & 96.36 \\
\hline Nickel & $62.41 \pm 0.69$ & 54.836 & 87.86 \\
\hline Potassium & $2034 \pm 29$ & 1952.96 & 96.02 \\
\hline
\end{tabular}

$\mathrm{a}=$ Mean \pm Standard Deviation; na $=$ not analyzed.

Table 4. Physicochemical parameters in the tap water by counties $(n=3)$.

\begin{tabular}{ccccc}
\hline County & Setting & $\mathrm{pH}$ & EC $(\mu \mathrm{S} / \mathrm{cm})$ & TDS $(\mathrm{ppm})$ \\
\hline Canon & Rural & 7.95 & 323.67 & 162.33 \\
Coffee & Rural & 7.54 & 112.20 & 56.13 \\
Warren & Rural & 7.90 & 286.00 & 142.00 \\
Rutherford & Urbanizing & 7.14 & 177.90 & 89.20 \\
Williamson & Urbanizing & 7.76 & 181.80 & 90.43 \\
Davidson & Urban & 7.61 & 175.23 & 87.63 \\
& & $6.5-8$ & - & 500 \\
\hline
\end{tabular}

EPA MCL = Environmental Protection Agency Maximum Contaminant Limit.

NC). The lognormal transformation was conducted to generate normally distributed data. Since data obtained from the ICP was not normally distributed. Non-parametric statistical tests such as Kruskal Wallis and Wilcoxon Rank Sum 
tests were performed. Kruskal-Wallis test was used to determine if there were significant differences between the variables. The significance level used for all tests was $95 \%$ (or $\alpha=0.05$ ).

\section{Results and Discussion}

\subsection{Comparison of Heavy Metals among the Counties}

Statistical analysis showed that the selected urban areas had a significantly higher percentage of heavy metals than those of rural areas (Figure 3). Additionally, heavy metals (Arsenic, Cadmium, Cobalt, Lead, Mercury, and Silver) concentrations were highest in urbanized areas relative to rural settings. However, the values were below the Maximum Contaminant Levels (MCLs).

No differences were detected in heavy metal concentrations among the six counties $\left(\chi^{2}=4.07, \mathrm{df}=5, \mathrm{P}=0.5395\right)$. However, when counties were compared for radioactivity (presence of uranium $\mathrm{U}$ and rubidium $\mathrm{Rb}$ ), significant difference were observed $\left(\chi^{2}=25.47 ; \mathrm{df}=5 ; \mathrm{P}=0.0001\right)$. Canon county had significantly more radioactive elements than the other counties (Figure 4 ). The reason could be attributed to the underlying bedrock and natural radioactive elements.

\subsection{Principal Component and Cluster Analysis}

From the Principal component analysis of all the elements, it was found that the first 7 components explain $90 \%$ of the variations among the variables (Table 5; Figure 5). Also Component 1 and 2 cumulatively accounted for $53 \%$ of the variability in the dataset (Table 5).

Cluster analysis or clustering is the task of grouping a set of objects in such a way that the objects in the same group (called a cluster) are more similar (in some sense or another) to each other than to those in other groups (clusters). It is the main task of exploratory data mining, and a common technique for data analysis, used in many fields. Cluster analysis (agglomeration, nearest neighbor

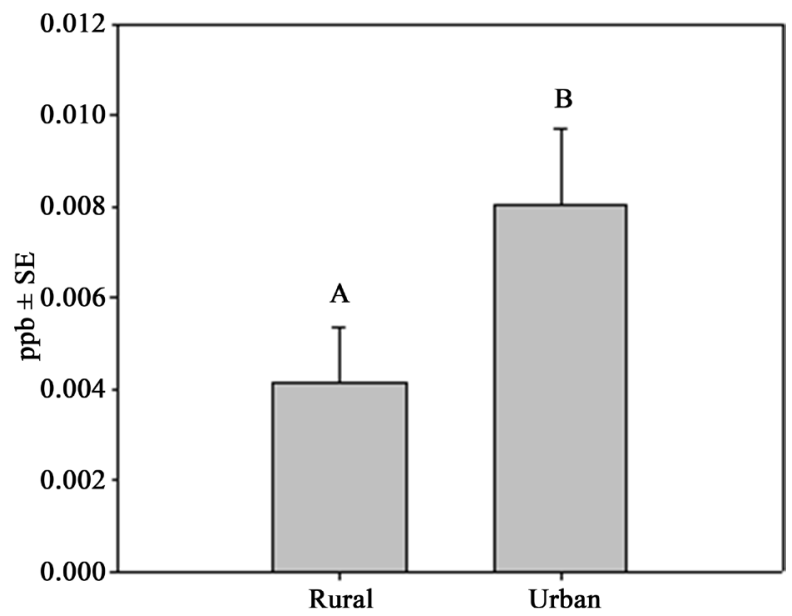

Figure 3. Mean \pm SE of heavy metal concentration Urban vs. Rural Counties. Bars with different letters were significantly different $\left(\chi^{2}=4.31\right.$; $\mathrm{df}=1$; $\left.\mathrm{P}<0.038\right)$ (Wilcoxon Rank Sum Test [17]. 


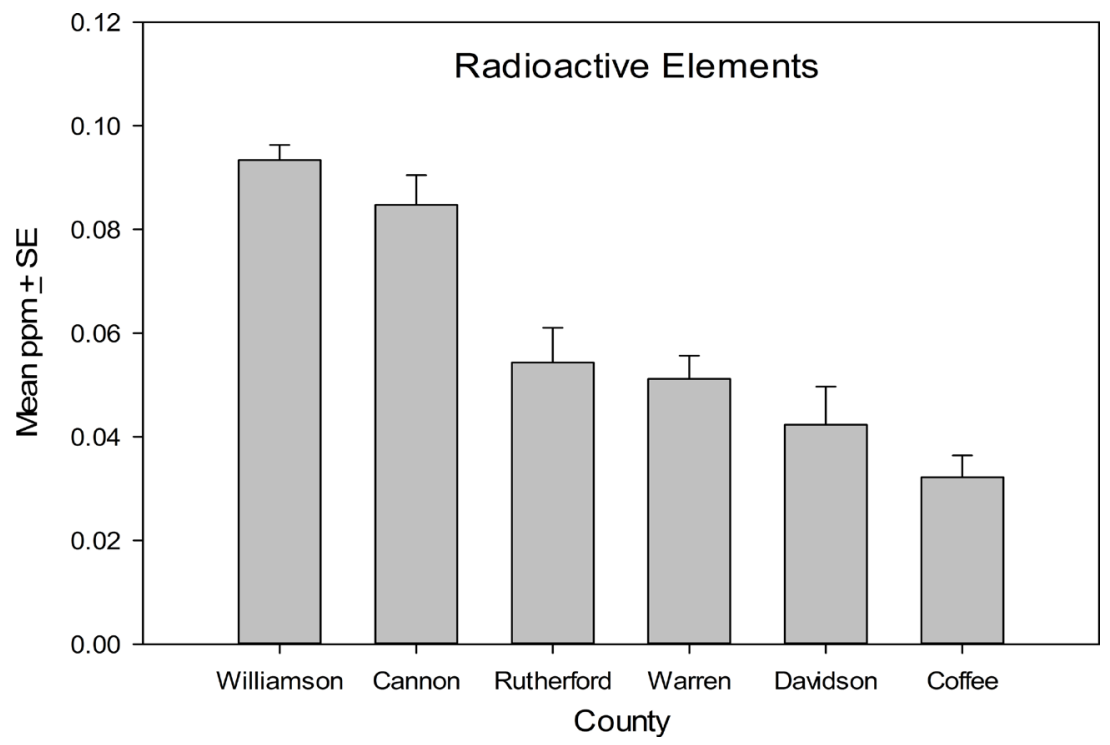

Figure 4. Mean $( \pm \mathrm{SE})$ concentration of radioactive ions (uranium and radium) $(\mathrm{mg} / \mathrm{L}$ ) among the six studied counties.

Table 5. Eigenvalues ${ }^{\star}$ of the components (elements analyzed).

\begin{tabular}{ccccc}
\hline Component & Eigenvalue & Difference & Proportion & Cumulative \\
\hline 1 & 8.42 & 3.09 & 0.32 & 0.32 \\
2 & 5.33 & 2.10 & 0.21 & 0.53 \\
3 & 3.23 & 0.87 & 0.12 & 0.65 \\
4 & 2.36 & 0.54 & 0.09 & 0.74 \\
5 & 1.81 & 0.37 & 0.07 & 0.81 \\
6 & 1.45 & 0.53 & 0.06 & 0.87 \\
7 & 0.91 & 0.06 & 0.04 & 0.90 \\
8 & 0.85 & 0.24 & 0.03 & 0.94 \\
9 & 0.61 & 0.23 & 0.01 & 0.96 \\
10 & 0.38 & 0.16 & 0.01 & 0.98 \\
11 & 0.22 & 0.01 & 0.01 & 0.98 \\
12 & 0.21 & 0.11 & 0.00 & 0.99 \\
13 & 0.10 & 0.04 & 0.00 & 1.00 \\
14 & 0.06 & 0.01 & 0.00 & 1.00 \\
15 & 0.04 & 0.03 & 0.00 & 1.00 \\
16 & 0.01 & 0.01 & 0.00 & 1.00 \\
17 & 0.00 & 0.00 & 0.00 & 1.00 \\
\hline & 0.00 & 0.00 & 0.00 \\
\hline
\end{tabular}

${ }^{*}$ The first seven components explain $90 \%$ of the variations among the variable's elements. The rest 31 of the components has been truncated due to redundancy.

method, squared Euclidean distance and z-score transformation) produced dendrogram plot (Figure 6) from all the major inorganic concentrations (except Fl$\mathrm{Cl}-\mathrm{Ni}, \mathrm{Co}, \mathrm{Fe}, \mathrm{Sn}$ ) in drinking water types. The hierarchical agglomerative 


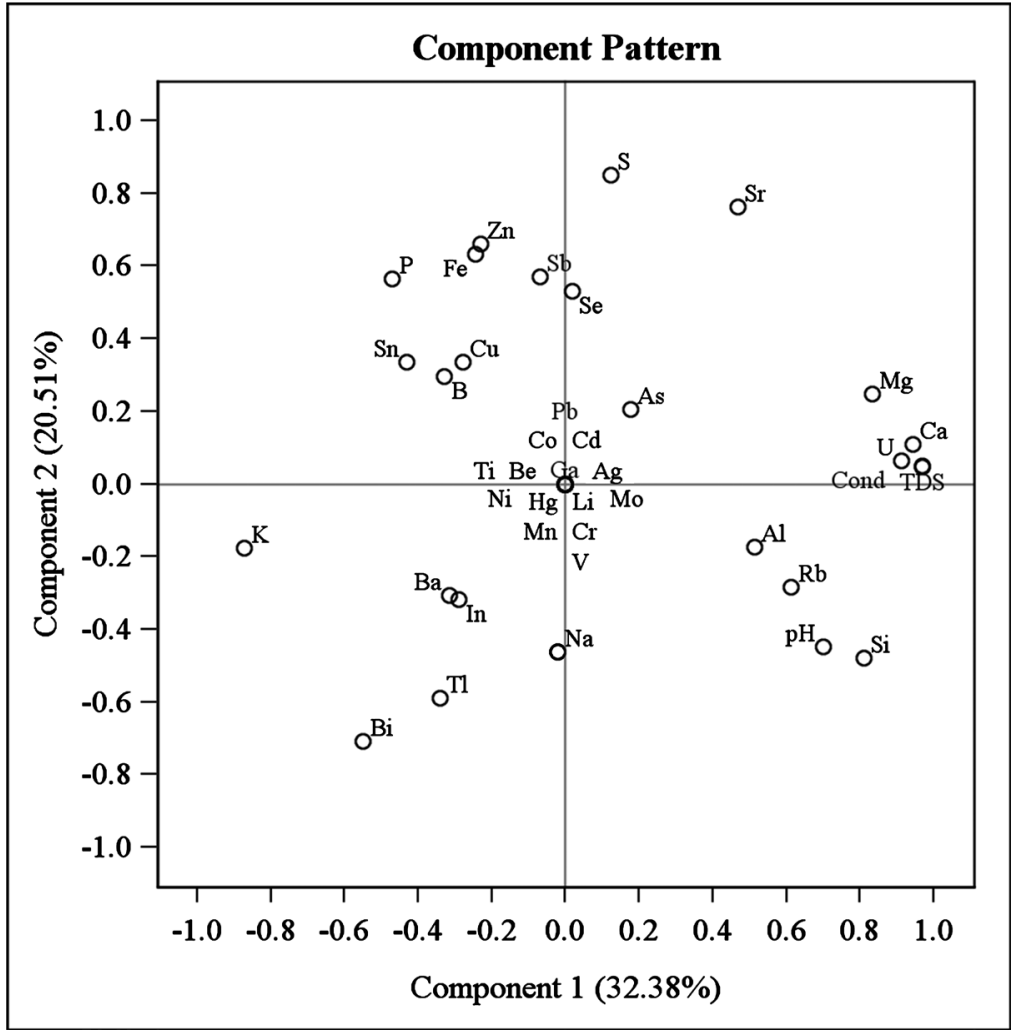

Figure 5. Dissolved PCA analysis for all the elements detected.

Dendrogram using Single Linkage

Rescaled Distance Cluster Combine

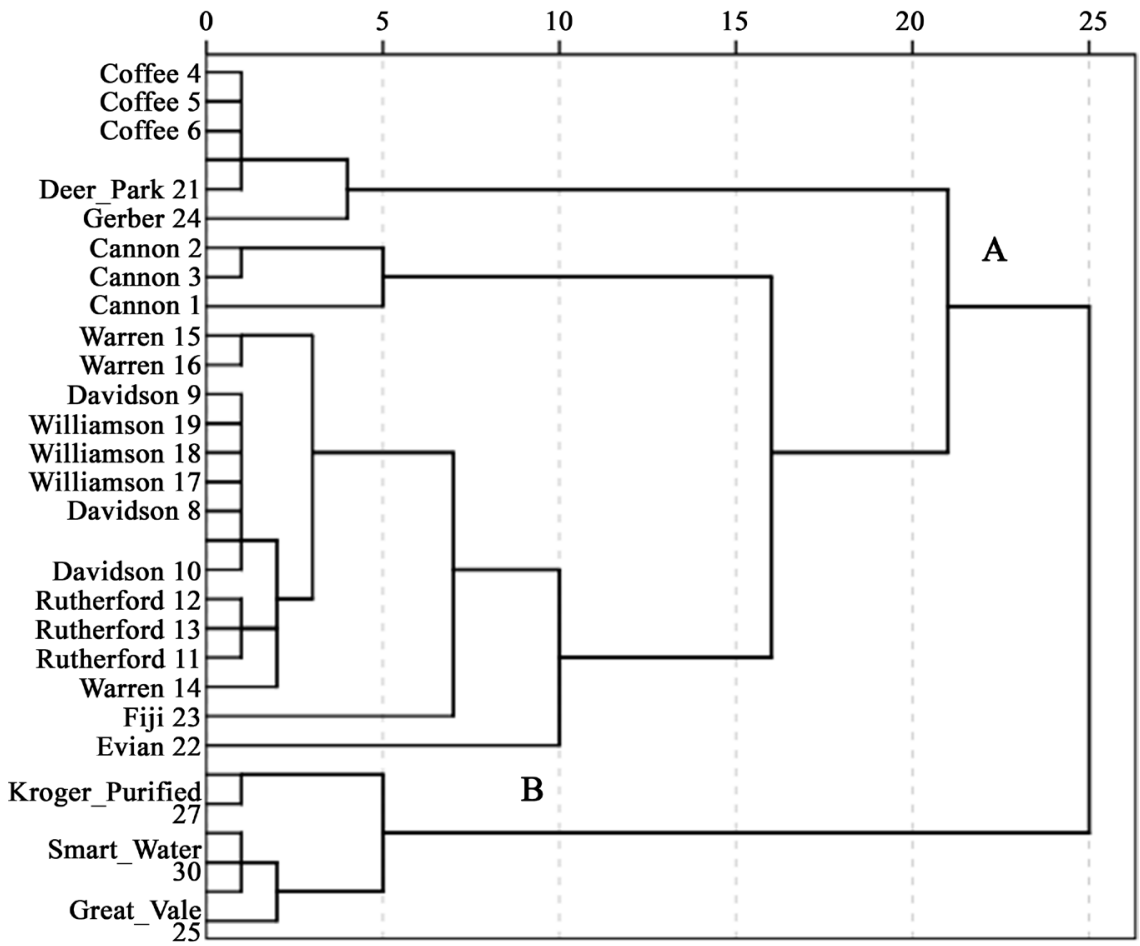

Figure 6. Hierarchical cluster analysis, Ward method, squared Euclidean distance, $\mathrm{z}$ transformation. The numbers are cases. 
procedure resulted in two major clusters. The dendrogram plot suggests that tap water in these counties was very similar to the bottled water types.

It is noteworthy that most of the toxic metals were below the EPA recommended limit. However, more epidemiological studies are required to see the effect of several of the elements.

The data described herein, tend to indicate that there is minimal or no significant difference between bottled water and tap water. However, some chemical constituents like calcium and magnesium tend to be higher in tap water collected from rural counties than in the urbanizing counties. Similarly, the same elements tend to be higher in natural spring bottled water, indicating that the occurrence of these elements might be due to the geology of the drinking water. In middle Tennessee for example, there is an abundance of limestone rocks. These rocks are prevalent in rural counties of middle Tennessee. Due to the industrialization and urban sprawl in the urban counties, there are less rocks. As a result, the concentration of calcium and magnesium tend to be lower in tap water. Also, the concentrations of fluoride were relatively higher in tap water. Fluoride was below the detection limits in bottled water; indicating that manufacturers of the bottled water brands seldom add this element (fluoride) to bottled water. Certainly, there is a dire need to conduct more epidemiological studies to see the effect of several of these elements in drinking water sources.

\section{Conclusion}

It is not uncommon for consumers to pay three (3) dollars for $20 \mathrm{fl} \mathrm{oz}(591 \mathrm{ml})$ of bottled water. Certainly, many factors account for USA consumers' enthusiasm for bottled water. Central among these factors include portability, safety, convenience, value, and health-fulness. United States residents drink more bottled water annually than any other beverage, other than carbonated soft drinks. The study tends to dispel the myth that bottled water is better than tap water or vice versa.

\section{Acknowledgements}

The authors are greatly thankful to Dr. Jason Oliver, Department of Agricultural and Environmental Sciences, College of Agriculture, Tennessee State University.

\section{Conflicts of Interest}

The authors declare no conflicts of interest regarding the publication of this paper.

\section{References}

[1] Ikem, A., Odueyungbo, S., Egiebor, N.O. and Nyavor, K. (2002) Chemical Quality of Bottled Waters from Three Cities in Eastern Alabama. The Science of the Total Environment, 285, 165-175. https://doi.org/10.1016/S0048-9697(01)00915-9

[2] Duan, W., Chen, G., Chen, C., Sanghvi, R., Iddya, A., Walker, S., et al. (2017) Electrochemical Removal of Hexavalent Chromium Using Electrically Conducting Carbon 
Nanotube/Polymer Composite Ultrafiltration Membranes. Journal of Membrane Science, 531, 160-171. https://doi.org/10.1016/j.memsci.2017.02.050

[3] Roh, T., Lynch, C.F., Weyer, P., Wang, K., Kelly, K.M. and Ludewig, G. (2017) Low-level Arsenic Exposure from Drinking Water Is Associated with Prostate Cancer in Iowa. Environmental Research, 159, 338-343. https://doi.org/10.1016/j.envres.2017.08.026

[4] IARC (2009) Arsenic and Arsenic Compounds. IARC Monographs on the Evaluation of Carcinogenic Risks to Humans. International Agency of Research on Cancer, 100C-6.

[5] Erickson, M.L. and Barnes, R.J. (2005) Glacial Sediment Causing Regional-Scale Elevated Arsenic in Drinking Water. Ground Water, 43, 796-805.

https://doi.org/10.1111/j.1745-6584.2005.00053.x

[6] Michael, H.A. (2013) An Arsenic Forecast for China. Science, 341, 852-853. https://doi.org/10.1126/science.1242212

[7] USEPA (2017) National Primary Drinking Water Regulations. U.S. Environmental Protection Agency, Washington DC.

https://www.epa.gov/ground-water-and-drinking-water/national-primary-drinking -water-regulations

[8] Morr, S., Cuartas, E., Alwattar, B. and Lane, J.M. (2006) How Much Calcium Is in your Drinking Water? A Survey of Calcium Concentrations in Bottled and Tap water and Their Significance for Medical Treatment and Drug Administration. HSS Journal, 2, 130-135. https://doi.org/10.1007/s11420-006-9000-9

[9] Samek, K. (2004) Unknown Quantity: The Bottled Water Industry and Florida's Springs. Journal of Land Use, 19, 569-595.

[10] Olson, E. D. (1999) Bottled Water: Pure Drink or Pure Hype? National Resources Defense Council.

https://www.nrdc.org/resources/bottled-water-pure-drink-or-pure-hype

[11] Postman, A. (2016) Lots of People Think Drinking Bottled Water Is Safer. Is It? The Truth about Tap. National Resource Defense Council. https://www.nrdc.org/stories/truth-about-tap

[12] Doria, M.F. (2010) Factors Influencing Public Perception of Drinking Water Quality. Water Policy, 12, 1-19. https://doi.org/10.2166/wp.2009.051

[13] Korn, M.G.A., de Andrade, J.B., de Jesus, D.S., Lemos, V.A., Bandeira, M.L.S.F., dos Santos, W.N.L., Bezerra, M.A., Amorim, F.A.C., Souza, A.S. and Ferreira, S.L.C. (2006) Separation and Preconcentration Procedures for the Determination of Lead Using Spectrometric Techniques: A Review. Talanta, 69, 16-24. https://doi.org/10.1016/j.talanta.2005.10.043

[14] Fang, Z.L. (1995) Flow Injection Atomic Absorption Spectrometry. John Wiley \& Sons, Chichester.

[15] ICP-OES/ICP-AES Principle. https://www.spectro.com/icp-oes-principle

[16] US Census Bureau (2012). https://www.census.gov/programs-surveys/acs/guidance/comparing-acs-data/2012. $\underline{\mathrm{html}}$

[17] SAS Institute Inc. (2003) SAS ${ }^{\circledR}$. SAS Institute Inc., Cary, NC. 